\title{
Graft nephrectomy in children
}

\author{
Benedict L. Phillips ${ }^{1}$ • Chris J. Callaghan ${ }^{1}$
}

Received: 23 February 2017 / Revised: 6 April 2017 / Accepted: 6 April 2017 /Published online: 19 June 2017

(C) The Author(s) 2017. This article is an open access publication

\begin{abstract}
Kidney transplantation is recognised as the gold standard treatment of end-stage renal disease in most children, with excellent graft survival rates. When graft failure occurs, renal transplant recipients (RTRs) have the option of removal of the transplant (graft nephrectomy [GN]), or leaving the failed transplant in situ. The aims of this review are to discuss the indications for GN, surgical techniques, outcomes after GN (including risks of allosensitisation and the impact on subsequent transplants), and the possible role of routine GN in the asymptomatic RTR with a failed renal allograft. Literature in both the pediatric and adult renal transplant fields is reviewed. We also discuss how future research in this area could advance our knowledge of which patients to select for $\mathrm{GN}$, and the most appropriate surgical approach.
\end{abstract}

Keywords Pediatric $\cdot$ Renal $\cdot$ Transplant $\cdot$ Graft nephrectomy

$\begin{array}{ll}\text { Abbreviations } \\ \text { DSA } & \text { Donor-specific antibody } \\ \text { EC } & \text { Extra-capsular } \\ \text { GN } & \text { Graft nephrectomy } \\ \text { IC } & \text { Intra-capsular } \\ \text { RAE } & \text { Renal artery embolisation } \\ \text { RTR } & \text { Renal transplant recipient } \\ \text { RDS } & \text { Renal data system }\end{array}$

Chris J. Callaghan

chris.callaghan@gstt.nhs.uk

1 Department of Nephrology and Transplantation, Guy's Hospital and the Evelina London Children's Hospital, London, UK

\section{Introduction}

Renal transplantation is widely recognised as the gold standard treatment of end-stage renal disease in children. Graft survival rates are excellent, with pediatric renal transplant recipients (RTRs) from living donors and deceased donors having 5-year graft survival of $83 \%$ and $71 \%$ respectively [1]. However, $20 \%$ of children with a renal transplant have a failing graft, most commonly due to chronic rejection (36\%), acute rejection (13\%), or vascular thrombosis (7\%) [1]. Unlike recipients of failing heart, lung, or liver transplants, RTRs with failing grafts have access to a long-term form of organ support, i.e. dialysis. As a result, RTRs have the option of leaving a failed allograft in situ.

The alternative is surgical removal of the failed graft (graft nephrectomy [GN]). Previous studies have shown that more than half of children with failed renal allografts undergo GN $[2,3]$, suggesting that GN occurs frequently in the pediatric RTR population. Children with graft failure within a year of transplantation are four times more likely to undergo GN [2]. However, relatively little has been written in the pediatric literature on this subject, and to our knowledge, only one national guideline has been published [4]. In addition, it is not known whether or not failed renal allografts should be routinely removed, i.e. in asymptomatic RTRs. This is of particular importance in pediatric RTRs because of the need to avoid HLA sensitisation, and therefore optimise the child's opportunity to receive further renal transplants in the future [5].

The aim of this review is therefore to examine the role of $\mathrm{GN}$ in children. This review focuses on the indications for $\mathrm{GN}$, surgical techniques (including non-surgical approaches to graft devascularisation), outcomes after GN, risks of allosensitisation after GN, and the impact on subsequent outcomes after re-transplantation. Also, we discuss the 
management of immunosuppression after GN. Finally, we consider the possible role of routine GN in the RTR with a failed graft, and the direction of future research in this area.

\section{Indications}

Widely accepted indications for GN in children can be divided into absolute and relative groups. Absolute indications include:

1. Unsalvageable acute venous graft thrombosis: GN should be performed to prevent graft rupture and catastrophic bleeding.

2. Unsalvageable acute arterial graft thrombosis: GN should be performed to prevent the high risk of graft necrosis and subsequent infection that is likely to occur in the absence of a collateral blood supply to the kidney transplant.

3. Graft malignancy not appropriate for treatment with less invasive strategies, such as partial nephrectomy $[6,7]$, radiofrequency ablation [7] or cryotherapy [8].

Relative indications for GN include:

1. Localising signs and/or symptoms (e.g. haematuria, graft pain) indicating a chronic alloimmune response in a failed or failing renal transplant. Some patients may also have non-specific malaise, increased inflammatory markers, and erythropoietin resistance [9]. Other causes of these features should be excluded before considering GN, e.g. with imaging, urine culture, cystoscopy etc.

2. Recurrent or severe graft pyelonephritis, not responding to appropriate antimicrobial therapy.

3. To enable complete withdrawal of immunosuppression, e.g. in post-transplant lymphoproliferative disorder nonresponsive to standard treatment [10], or persistent BK nephropathy resistant to reduced immunosuppression and anti-virals [11].

4. To create space for re-transplantation: cross-sectional imaging is usually required to define the anatomy and provide a more objective analysis of the space available for a re-transplant. GN may be performed at the time of transplantation, or before listing.

\section{Surgical technique}

There are three recognised surgical techniques for GN: intraperitoneal; extraperitoneal with an intra-capsular (IC) approach; or extraperitoneal with an extra-capsular (EC) approach.

The favoured technique is determined by multiple factors, including the original method of graft implantation, the timing of GN after transplantation, the possible presence of intraperitoneal disease, and the surgeon's preference.

Pediatric RTRs weighing less than $15-20 \mathrm{~kg}$ at the time of transplantation often undergo intraperitoneal kidney implantation, although approaches vary among units (Fig. 1a) [12, 13]. This enables adequate access to larger recipient vessels (e.g. the aorta and inferior vena cava) and the necessary space for the graft to lie in. Intraperitoneal kidney grafts can only be explanted via an intraperitoneal approach, i.e. entering into the peritoneal cavity.

Pediatric RTRs with grafts implanted into the extraperitoneal space account for the majority of cases, typically in children weighing more than $15-20 \mathrm{~kg}$ at the time of transplantation (Fig. 1b). Extraperitoneal implantation is generally preferred in larger children to avoid the complications associated with entering the peritoneal cavity (e.g. visceral injury, adhesions), to access extraperitoneal structures such as the iliac blood vessels and bladder, and for the ease of subsequent graft biopsy. GN in this patient group may be performed via either intraperitoneal or extraperitoneal (IC or EC) approaches (Fig. 2). It is important to consider the risks and benefits of each technique.

Following extraperitoneal transplantation, the capsule of the kidney becomes progressively adherent to extraperitoneal tissues. If GN is performed within 2-6 weeks of transplantation, the kidney can usually be explanted in its entirety (EC approach). After 2-6 weeks post-transplantation, there is no clear plane between native tissues and the allogeneic renal capsule, making an EC approach increasingly challenging. Therefore, removal of the extraperitoneal graft is usually achieved by bluntly separating the renal capsule from the underlying parenchyma (IC approach; Fig. 2) [14]. With the IC approach, it is more difficult to access the graft vessels and ureter, leading to ligation nearer the graft hilum, and resulting in more allogeneic tissue being left in situ. Alternatively, the surgeon may enter the peritoneal cavity to then excise a graft placed extraperitoneally; this is also an intraperitoneal approach. Better access to the donor blood vessels and ureter is therefore possible. Removing the ureter and blood vessels entirely is preferable to avoid allosensitisation, but exposes the patient to increased surgical risk, including longer operating times, bladder leaks, need for post-operative bladder catheterisation, vascular reconstruction and its complications.

Each of the three surgical approaches described above has its advantages and disadvantages (Table 1). These techniques are almost always performed as open surgery, although laparoscopic GN of a graft placed intraperitoneally has been described [15].

\section{Non-surgical devascularisation}

Renal artery embolisation (RAE) is a minimally invasive alternative to GN and has been used in both adults and children 
Fig. 1 a Cross-section of the abdomen as seen on CT.

Intraperitoneal kidney transplant. The kidney is implanted into the peritoneal cavity (shaded in green) and is anastomosed on the aorta and inferior vena cava (IVC). b Cross-section of the pelvis as seen on CT.

Extraperitoneal kidney transplant. The kidney is implanted in the right iliac fossa (RIF), outside of the peritoneum (marked in dark green), within the extraperitoneal space (shaded in purple) a

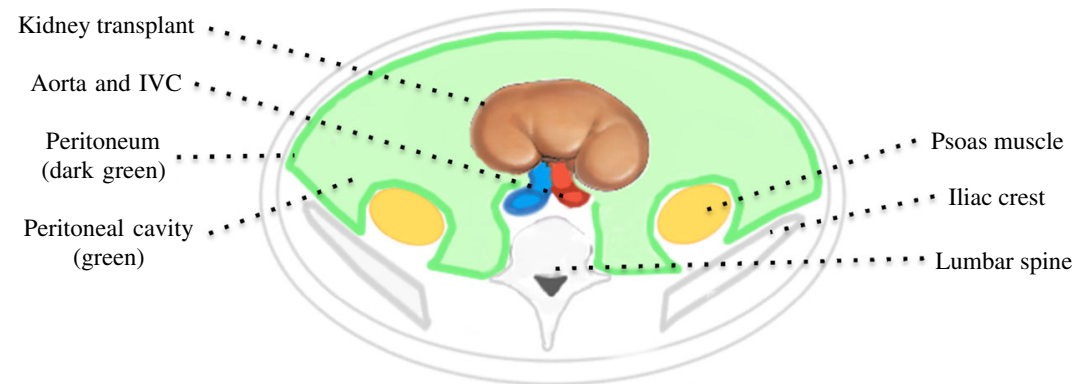

b

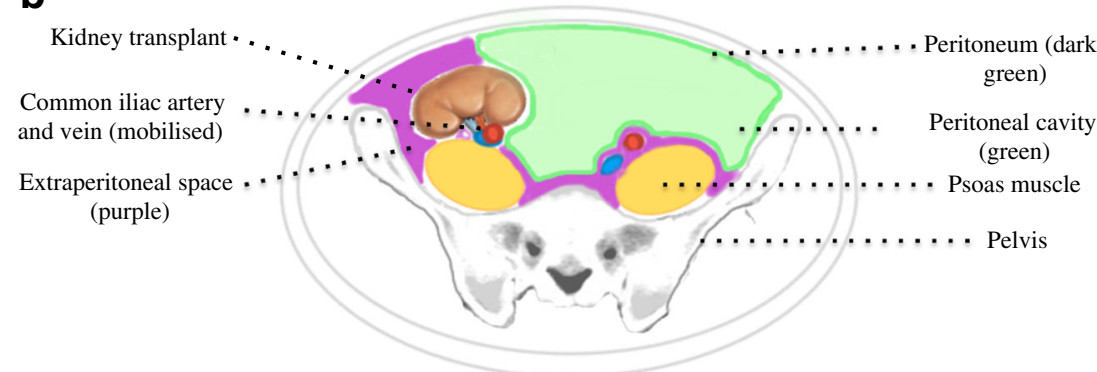

CT - computerized tomography, IVC - inferior vena cava, RIF -right iliac fossa
[16-19]. Devascularisation of the allograft is achieved by percutaneous puncture of the femoral artery, followed by induction of graft thrombosis using ethanol, stainless steel coils, polyvinyl alcohol or tris acryl microspheres. The aim of RAE is complete infarction of the allograft; however, incomplete thrombosis of the graft occurs in between 15 and $35 \%$ of cases [20-23].
RAE may be advantageous over GN as it appears to reduce the risk of some of the complications associated with open surgery, including blood loss and requirement for blood transfusion [24]. RAE is also associated with reduced pain and length of stay in hospital [18]. However, RAE can be associated with other complications, such as post-embolisation syndrome (fever, graft pain, haematuria) and necrotic pyelonephritis, both
Fig. 2 Cross-section of the abdomen of a RIF kidney transplant in the extraperitoneal space. The extra-capsular $(E P)$ and intra-capsular $(I C)$ approaches to graft nephrectomy are marked in black




Table 1 The different surgical techniques for graft nephrectomy (GN), with relative advantages and disadvantages

\begin{tabular}{|c|c|c|}
\hline Approach & Advantages & Disadvantages \\
\hline Intraperitoneal & $\begin{array}{l}\text { Only feasible access to } \\
\text { intraperitoneal grafts } \\
\text { More complete removal } \\
\text { of allogeneic tissues } \\
\text { Likely reduced rate of } \\
\text { lymphoceles and collections }\end{array}$ & $\begin{array}{l}\text { Risk of damaging intraperitoneal } \\
\text { structures (e.g. bowel) } \\
\text { Risk of post-operative ileus } \\
\text { Risk of complications from bowel } \\
\text { adhesions (e.g. obstruction) }\end{array}$ \\
\hline Extra-capsular & $\begin{array}{l}\text { More complete removal of } \\
\text { allogeneic tissues } \\
\text { Easy plane in the early } \\
\text { post-transplant phase } \\
\text { Good access to the blood } \\
\text { vessels and bladder } \\
\text { Avoidance of the bowel }\end{array}$ & $\begin{array}{l}\text { Challenging plane after the early } \\
\text { post-transplant phase } \\
\text { Risk of lymphoceles and collections }\end{array}$ \\
\hline Intra-capsular & $\begin{array}{l}\text { Accessible plane after the } \\
\text { early post-transplant phase } \\
\text { Avoidance of bowel }\end{array}$ & $\begin{array}{l}\text { Less complete removal of } \\
\text { allogeneic tissues } \\
\text { Possible increased blood loss from } \\
\text { the bare parenchyma } \\
\text { More difficult access to the } \\
\text { blood vessels and bladder }\end{array}$ \\
\hline
\end{tabular}

affecting approximately $10 \%$ of patients [17]. These graftrelated complications can be avoided by using RAE as a "neo-adjuvant" intervention, one or two days before GN. This combined approach appears to reduce the intraoperative blood loss [24-26] and operative time of GN [24, 26]. Less common complications of RAE include arterial pseudoaneurysm [27] and coil migration with limb embolisation [28].

At present, RAE is not widely used, and the patient groups most likely to benefit from RAE, GN, or combined RAE-GN, are as yet poorly defined in the pediatric RTR population. RAE alone may be most useful in patients with a prohibitively high operative risk (e.g. severe cardiorespiratory disease), with combined RAEGN reserved for those at a significantly increased risk of intraoperative bleeding [4].

\section{Outcomes after GN}

Outcomes after GN can be analysed on the basis of patient age group (pediatric or adult), surgical approach (intraperitoneal, or extraperitoneal EC/IC), or timing of surgery (early or late post-transplant). Outcomes may be related directly to the surgery in the short-term, or may be immunological with longterm sequelae.

\section{Short-term morbidity and mortality}

The literature on outcomes after GN contains many retrospective analyses, but most are limited by their study design. In addition, many reports do not specify which GN surgical technique was used. No randomised controlled trials (RCTs) are available.

In children, only two papers have been published on outcomes after GN. The largest analysis $(n=53)$ was performed by Zerouali et al. [3]. Children undergoing GN within a month post-transplant had surgery via the EC approach $(n=19)$; all others had grafts removed via the IC approach $(n=44)$. Complications were not stratified according to the surgical approach. There were no early post-operative deaths following GN, although the follow-up period was not defined. Twenty per cent of children developed complications after GN, including wound infection (9\%), deep vein thrombosis $(5 \%)$ and chest infection (2\%). Median length of stay in hospital was 19.5 days; no comment was made on the need for blood transfusions. It should be noted that this study was performed on GNs between 1977 and 1999, i.e. before the modern immunosuppression era. In a more recent analysis of 18 children who underwent GN, none of the patients had major intra- or post-operative complications requiring a secondary operation, unplanned intensive care admission or blood transfusion within the first 14 days [2]. The surgical approach was not described.

In adults, the largest study examining outcomes after GN in adults was published by Johnston et al. [29], who used the US Renal Data System (RDS) database. Of the 6,213 adults who underwent GN between 1995 and 2003, the reported mortality rate was $1 \%$ during hospital admission, and $5 \%$ within 90 days of surgery. Death was more common in patients undergoing nephrectomy for graft failure within a year of transplantation, presumably because of the heavier immunosuppressive 
burden during this period. Sepsis was the most common complication of GN, affecting $6 \%$ during their hospital stay and $11 \%$ within 90 days of GN. There have been a number of other retrospective analyses examining early post-operative outcomes following GN in adults, with a complication rate of $20-60 \%$, and a mortality rate of $0-7 \%$ [30-33]. Sepsis appears to be the most common complication.

There are no studies comparing IC and EC GN techniques in children, and only small analyses in adults. Vavallo et al. [34] examined the outcomes of 89 adults undergoing GN; 51 by EC GN and 32 by IC GN. Overall, 9 patients (10\%) had bleeding, with $6(7 \%)$ having infection/sepsis, and $4(4 \%)$ developing a lymphocele. Two patients needed surgery for arterial damage. No deaths were reported. Surprisingly, mean operating time, blood loss, need for blood transfusion and perioperative complication rates of the two techniques were similar. Overall, $10 \%$ of patients required a blood transfusion. The only difference observed between the outcomes after the two techniques was mean hospital length of stay, which was 13.8 days in the EC group and 7.6 days in the IC group $(p=0.01)$. Smaller studies comparing the IC and EC techniques have not shown a clear association between technique and blood loss [35-37].

Major vascular complications occur in approximately 5\% of cases and are associated with poor outcomes [38]. Complications include major haemorrhage requiring ligation of the external iliac artery, and pseudoaneurysm formation [38-41].

Although GN is associated with short-term morbidity and mortality, there is some evidence that long-term mortality in patients who undergo GN is less than those with a failed renal allograft who have not had a GN. A large analysis of the US RDS registry between 1994 and 2004 showed that, of 10,915 RTRs with failed grafts on dialysis, $31.5 \%$ underwent GN, which was associated with a reduced relative risk of death from all causes when compared with those who had not had GN. This difference persisted after risk adjustment for socioeconomic factors and co-morbidity burden (adjusted hazard ratio 0.68 ; 95\% confidence interval $0.63-0.74$ ) [42].

In summary, GN is major surgery, but post-operative mortality appears to be very low in children, with reasonable rates of major complications. As expected, mortality rates after GN in adults are higher. There is no strong evidence favouring one surgical approach over another with regard to short-term morbidity and mortality. Whichever surgical approach is used, careful surgery with meticulous haemostasis is advised [4].

\section{Allosensitisation and subsequent graft outcomes}

The avoidance of sensitisation to HLA (allosensitisation) is a critical issue in renal transplantation, particularly pediatric renal transplantation, where patients are expected to need more than one graft in their lifetime. Allosensitisation occurs through exposure to non-self HLA via a blood transfusion, transplantation, or pregnancy, resulting in the production of antibodies directed against HLA. The immunological pathways of HLA-Ab production have been fully described elsewhere [5]. The presence of HLA antibodies is associated with an increased risk of rejection and graft loss in current and subsequent transplants. After graft failure, broad HLA sensitisation (high panel reactive antibody [PRA]) results in reduced access to the donor pool, with longer waiting times and the potential morbidity and mortality associated with prolonged dialysis.

The impact of GN on allosensitisation and subsequent graft outcomes is difficult to determine because of multiple potential confounding factors. Most importantly, one of the major indications for GN is symptomatic graft rejection, implying that the recipient is sensitised before GN. In addition, GN may lead to the need for blood transfusion, and therefore the surgical technique and variation in transfusion practice will also have an impact on sensitisation. Finally, the management of immunosuppressant withdrawal after GN is not standardised, is poorly described in most papers, and is also highly likely to influence subsequent sensitisation after GN [43]. Examining change in PRA over the GN period attempts to control for some of the above factors, but may not take into account the potential absorptive capacity of the graft ("sponge hypothesis" [44]), which may also act as a confounding variable in retrospective analyses. Leaving allogeneic tissue in situ is more likely with the IC approach, and may also influence allosensitisation. These caveats should be kept in mind when considering the literature.

In pediatric RTRs, Minson et al. [2] performed a retrospective analysis of 34 children who had renal allograft failure. PRA was significantly higher for children following GN (mean PRA 87.9\%) compared with children who had not undergone GN $(65.2 \% ; p=0.0003)$. However, the relative change in PRA following GN was not recorded, meaning that the possibility that the GN group may have had higher PRA than the non-GN group even before the operation cannot be excluded. Indeed, the GN group had a higher incidence of biopsy-proven Banff II acute rejection before undergoing $\mathrm{GN}(p=0.04)$. Zerouali et al. did not observe any difference in PRA score between children who had GN $(n=63)$ and those who did not $(n=82)$ [3].

There have been two studies in adults indicating that the timing of GN is an important factor in allosensitisation. Sener et al. [45] found that patients who had GN following early graft failure ( $<6$ months) demonstrated a reduction in PRA score by $19 \%(p=0.02)$, whereas PRA score increased following late GN. Studies that did not take into account the timing of GN showed that GN was associated with an increase in detectable HLA-Ab and new DSA [46-50]. Analyses comparing IC and EC GN on allosensitisation were unable to detect a difference in PRA score between the two techniques $[35,37]$. 
The impact of GN on subsequent renal transplant outcomes is similarly ill-defined. There are no studies in pediatric RTRs, but in adults, Johnston et al. [29] found that patients undergoing GN following early graft failure ( $<12$ months) were at a lower risk of graft failure once retransplanted (HR 0.72, 95\% CI 0.56-0.94). In contrast, patients who had GN following late graft failure were at a significantly higher risk of subsequent graft failure (HR 1.20, 95\% CI 1.02-1.41).

One meta-analysis of PRA and subsequent graft outcomes after GN has been published by Wang et al. [51]. Eight retrospective analyses were identified, but only papers published in open access journals were included. The meta-analysis showed that patients undergoing GN had no difference in one-year graft or patient survival compared with those being re-transplanted without GN. GN was associated with a significantly higher increase in PRA score compared with the nonGN group (odds ratio 1.62, 95\% confidence interval 1.172.23). It should be noted that Wang's criterion for entry into the meta-analysis was asymptomatic non-functioning renal allografts ("routine GN"); however, of the 8 papers, 6 included GN performed for symptoms. The inclusion of nonrandomised observational studies introduces the possibility that the confounding factors discussed above might influence outcomes, and therefore it is difficult to draw meaningful conclusions from these results.

\section{Immunosuppression after GN}

The management of immunosuppression after GN in children is a complex area, with little evidence supporting practice. Even in the adult field, the evidence base is limited.

Withdrawal of immunosuppression is an independent predictor of allosensitisation after GN $[46,52]$; this is not surprising given that allogeneic tissue is likely to be present after GN, as discussed above. There is therefore some rationale for maintaining immunosuppression following $\mathrm{GN}$; however, this needs to be balanced with the risks of remaining on immunosuppression whilst on dialysis (e.g. infection [53, 54], cardiovascular disease and malignancy). Current guidelines recommend that all immunosuppression, apart from steroids, should be stopped immediately after GN [4]. There should be subsequent gradual withdrawal of steroids.

However, these guidelines were aimed primarily at adult RTRs and considerations with pediatric RTRs are obviously different, as children are more likely to have live donors available after graft loss, and they do not wait as long on the deceased donor waiting list as adults. We would therefore suggest that the risk of HLA sensitisation might be minimised after GN in children by maintaining immunosuppression with at least two agents. This is based on studies in adults that identified prolonged immunosuppression as a protective factor in reducing antibody levels after graft failure $[50,55]$. This approach to immunosuppression management after GN should be modified for children at a high risk of infection or cancer whilst on dialysis, or in those countries where deceased donor waiting times for children are prolonged (e.g. more than 1 year).

\section{Is there a role for routine GN?}

Routine GN can be defined as GN performed for a failed graft in an asymptomatic RTR, i.e. without the pathological conditions discussed in the section 'Indications' above. Routine GN does not appear to be widely practised, with less than $5 \%$ of transplant surgeons in the USA carrying these out in adult RTRs [56].

Del Bello et al. described their experience of performing routine ("systematic") GN in 17 adult RTRs whose grafts had failed [46]. Patients in this study had all immunosuppressants (other than steroids) stopped when their grafts failed and dialysis was started; steroids were ceased 6 months after dialysis was initiated. The timing of routine GN after dialysis and surgical technique were not described. After routine GN, average hospital stay was 6 days, and $30 \%$ of patients had a complication during their stay; $35 \%$ required a blood transfusion. Del Bello et al. showed that there was no difference in the emergence of donor-specific HLA antibodies (class I or II) in the routine GN group compared with a group of patients having GN for symptoms/signs $(n=31)$. Patients from a historical cohort who had not undergone GN, but had the same immunosuppressive withdrawal regimen, had lower DSAs at the last follow-up than the routine GN group (52\% vs $82 \%$ ). This study was non-randomised and many centres would have continued immunosuppressants for longer after graft failure. The impact of routine GN on fluid balance and inter-dialytic weight gains were not assessed.

Therefore, there is no strong evidence to support the use of routine GN at present. The decision to perform GN should be made having considered the risks and benefits, and on a caseby-case basis.

\section{Directions of future research}

The current literature on GN in pediatric RTRs is, in general, difficult to interpret, as the number of reports is small. Even in adults, the evidence base is limited, and many papers have insufficient information on the timing of GN, the surgical technique used, and the immunosuppression withdrawal strategy after graft failure or GN. Future analyses should contain detailed information on the above to provide an evidence base to guide clinicians caring for children with failed renal allografts.

The only feasible way of definitively determining the role of routine GN in clinical practice is by carrying out an RCT. 
This should be performed in adults first, owing to greater patient numbers, ethical considerations, and given the complexities of intra-peritoneal graft removal and the relatively higher chance of blood transfusion with pediatric surgery. If completed in adults, trials will be required in children given the high requirement for future re-transplantation in the pediatric renal failure population.

\section{Summary and conclusions}

There are widely-accepted absolute and relative indications for GN. Routine GN for failing grafts without these indications is not commonly practiced, and there is little evidence to support this approach. The three main surgical techniques for GN have been defined. Although there is no clear evidence to support one approach over the other, we suggest that as much allogeneic tissue should be removed as possible, to minimise the risk of subsequent HLA sensitisation. This is of particular importance in children. Meticulous surgical technique to avoid blood transfusion is also essential. RAE may be used as an alternative to, or in a "neo-adjuvant" intervention with, GN. RAE alone may be most useful in patients with a high operative risk or used before GN to reduce intraoperative blood loss and operative time.

The mortality rate of GN in children appears to be very low; complications affect $20 \%$ of children, with sepsis being the most common complication. The impact of GN on allosensitisation and subsequent graft outcomes is difficult to determine because of multiple potential confounding factors. Indeed, children undergoing GN are likely to have a raised PRA score before the operation as the indication for GN is often rejection. Furthermore, weaning of immunosuppression leads to sensitisation independently of GN [52]. It is therefore not possible to definitively determine the causality of raised PRA score in this setting. The impact of GN on subsequent renal transplant outcomes is similarly ill-defined in children. However, in adults, GN following early graft failure appears to be associated with better subsequent graft survival in the re-transplanted kidney, and worse graft survival following late GN.

Studies reporting outcomes after GN should report sufficient variables to enable meaningful comparisons with others in the field. RCTs are needed to address the role of routine GN in the adult and pediatric RTR populations.

\section{Key summary points}

- The mortality rate of GN in children appears to be very low, with complications affecting approximately $20 \%$ of children.

- There are three main surgical techniques for performing GN and there is no clear evidence to support one approach over the others.
- As much allogeneic tissue should be removed as possible during GN to minimise the risk of subsequent HLA sensitisation.

- RAE may be used as an alternative to, or "neo-adjuvant" intervention with, GN.

- Routine GN for the failing graft in an asymptomatic RTR is not commonly practiced.

\section{Multiple choice questions (answers are provided following the reference list)}

1. Regarding the surgical techniques of graft nephrectomy, which of the following statements is FALSE?

a) All intraperitoneal grafts are explanted via the intraperitoneal approach.

b) The extra-capsular approach is preferred soon after transplantation, as the surrounding tissue has not yet become adherent to the capsule of the graft.

c) The intra-capsular approach is preferred late after transplantation as little allogeneic tissue is left in situ.

d) Renal artery embolisation may be used before graft nephrectomy to reduce intraoperative bleeding and transfusion requirements.

2. Regarding the indications for graft nephrectomy, which of the following statements is FALSE?

a) Unsalvageable acute arterial and/or venous graft thromboses are absolute indications for graft nephrectomy.

b) Minimally invasive strategies, such as renal artery embolisation, should be considered first for graft malignancy, before graft nephrectomy.

c) Graft nephrectomy can be performed at the time of retransplantation.

d) BK nephropathy is a relative indication for graft nephrectomy, if antiviral treatments have been unsuccessful.

3. Regarding allosensitisation, which of the following are NOT considered to be likely sensitising events?
a) Blood transfusion
b) Pregnancy
c) Transplantation
d) Plasma exchange

\section{Compliance with ethical standards}

Conflict of interest The authors declare that they have no conflict of interest. 
Open Access This article is distributed under the terms of the Creative Commons Attribution 4.0 International License (http:// creativecommons.org/licenses/by/4.0/), which permits unrestricted use, distribution, and reproduction in any medium, provided you give appropriate credit to the original author(s) and the source, provide a link to the Creative Commons license, and indicate if changes were made.

\section{References}

1. North American Pediatric Renal Trials and Collaborative Studies. Annual transplant report 2014. Available from https://web.emmes. com/study/ped/annlrept/annualrept2014.pdf. Accessed on 27 March 2017

2. Minson S, Munoz M, Vergara I, Mraz M, Vaughan R, Rees L, Olsburgh J, Calder F, Shroff R (2013) Nephrectomy for the failed renal allograft in children: predictors and outcomes. Pediatr Nephrol 28:1299-1305

3. Zerouali F, Levtchenko EN, Feitz WF, Cornelissen EA, Monnens LA (2004) Renal transplant nephrectomy in children: can an aggressive approach be recommended? Pediatr Transplant 8:561-564

4. Andrews PA, Standards Committee of the British Transplantation Society (2014) Summary of the British Transplantation Society guidelines for management of the failing kidney transplant. Transplantation 98:1130-1133

5. Rees L, Kim JJ (2015) HLA sensitisation: can it be prevented? Pediatr Nephrol 30:577-587

6. Olsburgh J, Zakri RH, Horsfield C, Collins R, Fairweather J, O'Donnell P, Koffman G (2016) TCC in transplant ureter-when and when not to preserve the transplant kidney. Am J Transplant 16: 704-711

7. Tillou X, Doerfler A, Collon S, Kleinclauss F, Patard JJ, Badet L, Barrou B, Audet M, Bensadoun H, Berthoux E, Bigot P, Boutin JM, Bouzguenda Y, Chambade D, Codas R, Dantal J, Deturmeny J, Devonec M, Dugardin F, Ferriere JM, Erauso A, Feuillu B, Gigante M, Guy L, Karam G, Lebret T, Neuzillet Y, Legendre C, Perez T, Rerolle JP, Salomon L, Sallusto F, Senechal C, Terrier N, Thuret R, Verhoest G, Petit J, Comité de Transplantation de l'Association Française d'Urologie (CTAFU) (2012) De novo kidney graft tumors: results from a multicentric retrospective national study. Am J Transplant 12:3308-3315

8. Tillou X, Guleryuz K, Collon S, Doerfler A (2016) Renal cell carcinoma in functional renal graft: toward ablative treatments. Transplant Rev (Orlando) 30:20-26

9. Lopez-Gomez JM, Perez-Flores I, Jofre R, Carretero D, RodriguezBenitez P, Villaverde M, Perez-Garcia R, Nassar GM, Niembro E, Ayus JC (2004) Presence of a failed kidney transplant in patients who are on hemodialysis is associated with chronic inflammatory state and erythropoietin resistance. J Am Soc Nephrol 15:2494 2501

10. Trofe J, Buell JF, Beebe TM, Hanaway MJ, First MR, Alloway RR, Gross TG, Succop P, Woodle ES (2005) Analysis of factors that influence survival with post-transplant lymphoproliferative disorder in renal transplant recipients: the Israel Penn international transplant tumor registry experience. Am J Transplant 5:775-780

11. Hirsch HH, Randhawa P, AST Infectious Diseases Community of Practice (2013) BK polyomavirus in solid organ transplantation. Am J Transplant 13 [Suppl 4]:179-188

12. Chandak P, Stojanovic J, Sivaprakasam R, Mamode N, Calder F, Olsburgh J, Drage M, Callaghan C, Taylor J, Koffman G, Taylor J, Marks S, Kessaris N (2015) Is there a difference in patient and graft survival in children weighing $<20 \mathrm{~kg}$ versus those weighing $>20 \mathrm{~kg}$ at the time of renal transplantation? [abstract]. Am J Transplant 15 [Suppl 3]:D218
13. Dharnidharka VR, Fiorina P, Harmon WE (2014) Kidney transplantation in children. N Engl J Med 371:549-558

14. Sutherland DE, Simmons RL, Howard RJ, Najarian JS (1978) Intracapsular technique of transplant nephrectomy. Surg Gynecol Obstet 146:950-952

15. Pagano D, Cintorino D, Li Petri S, di Francesco F, Ricotta C, Argento J, Echeverri GJ, Bertani T, Riva S, Gridelli BG, Spada M (2012) Laparoscopic approach for an intra-abdominal kidney allograft nephrectomy after pediatric transplantation: a case report. Transplant Proc 44:2036-2037

16. Muller A, Rouviere O (2015) Renal artery embolization-indications, technical approaches and outcomes. Nat Rev Nephrol 11: 288-301

17. Choe J, Shin JH, Yoon HK, Ko GY, Gwon DI, Ko HK, Kim JH, Sung KB (2014) Safety and efficacy of transarterial nephrectomy as an alternative to surgical nephrectomy. Korean J Radiol 15:472480

18. Capozza N, Collura G, Falappa P, Caione P (2007) Renal embolization as an alternative to surgical nephrectomy in children. Transplant Proc 39:1782-1784

19. Krause I, Cleper R, Belenky A, Atar E, Bar-Nathan N, Davidovits $M$ (2008) Graft intolerance syndrome in children with failed kidney allografts - clinical presentation, treatment options and outcome. Nephrol Dial Transplant 23:4036-4040

20. Cofan F, Real MI, Vilardell J, Montanya X, Blasco J, Martin P, Oppenheimer F, Gutierrez R, Talbot-Wright R, Alcover J (2002) Percutaneous renal artery embolisation of non-functioning renal allografts with clinical intolerance. Transpl Int 15:149-155

21. Delgado P, Diaz F, Gonzalez A, Sanchez E, Gutierrez P, Hernandez D, Torres A, Lorenzo V (2005) Intolerance syndrome in failed renal allografts: incidence and efficacy of percutaneous embolization. Am J Kidney Dis 46:339-344

22. Gonzalez-Satue C, Riera L, Franco E, Escalante E, Dominguez J, Serrallach N (2000) Percutaneous embolization of the failed renal allograft in patients with graft intolerance syndrome. BJU Int 86: 610-612

23. Larini P, Marcato C, Monaco D, Bresciani P, Capocasale E, Mazzoni MP, Dalla Valle R, Busi N (2005) Percutaneous renal artery embolisation of non-functioning allograft. Preliminary experience. Radiol Med 110:501-505

24. Neschis DG, Gutta R, Al-Qudah HS, Bartlett ST, Philosophe B, Schweitzer EJ, Flinn WR, Campos L (2007) Intraoperative coil embolization reduces transplant nephrectomy transfusion requirement. Vasc Endovasc Surg 41:335-338

25. Yeast C, Riley JM, Holyoak J, Ross G Jr, Weinstein S, Wakefield M (2016) Use of preoperative embolization prior to transplant nephrectomy. Int Braz J Urol 42:107-112

26. Al-Geizawi SM, Singh RP, Zuckerman JM, Requarth JA, Farney AC, Rogers J, Taussig J, Orlando G, Stratta RJ (2015) Role of allograft nephrectomy following kidney graft failure: preliminary experience with pre-operative angiographic kidney embolization. J Nephrol 28:379-385

27. Jain S, Nyirenda T, Yates J, Munver R (2013) Incidence of renal artery pseudoaneurysm following open and minimally invasive partial nephrectomy: a systematic review and comparative analysis. J Urol 189:1643-1648

28. Morales A, Gavela E, Kanter J, Beltran S, Sancho A, Escudero V, Crespo J, Pallardo LM (2008) Treatment of renal transplant failure. Transplant Proc 40:2909-2911

29. Johnston O, Rose C, Landsberg D, Gourlay WA, Gill JS (2007) Nephrectomy after transplant failure: current practice and outcomes. Am J Transplant 7:1961-1967

30. Secin FP, Rovegno AR, del Rosario BM, Marrugat RE, Davalos Michel M, Fernandez H (2003) Cumulative incidence, indications, morbidity and mortality of transplant nephrectomy and the most appropriate time for graft removal: only nonfunctioning transplants 
that cause intractable complications should be excised. J Urol 169: $1242-1246$

31. O'Sullivan DC, Murphy DM, McLean P, Donovan MG (1994) Transplant nephrectomy over 20 years: factors involved in associated morbidity and mortality. J Urol 151:855-858

32. Grochowiecki T, Szmidt J, Galazka Z, Nazarewski S, Bojakowska M, Bojakowski K, Swiercz P (2000) Influence of timing of transplant nephrectomy on surgical complications. Transplant Proc 32: 1381

33. Hansen BL, Rohr N, Svendsen V, Birkeland SA (1987) Graft failure and graft nephrectomy without severe complications. Nephrol Dial Transplant 2:189-190

34. Vavallo A, Lucarelli G, Bettocchi C, Tedeschi M, Palazzo S, Losappio V, Gesualdo L, Grandaliano G, Selvaggi FP, Battaglia M, Ditonno P (2012) Allograft nephrectomy: what is the best surgical technique? Transplant Proc 44:1922-1925

35. Freitas R, Malheiro J, Santos C, Costa R, Martins LS, Almeida M, Dias L, Castro-Henriques A, Cabrita A, Silva-Ramos M, Almeida R (2015) Allograft nephrectomy: a single-institution, 10-year experience. Transplant Proc 47:992-995

36. Mazzucchi E, Nahas WC, Antonopoulos IM, Piovesan AC, Ianhez LE, Arap S (2003) Surgical complications of graft nephrectomy in the modern transplant era. J Urol 170:734-737

37. Touma NJ, Sener A, Caumartin Y, Warren J, Nguan CY, Luke PP (2011) Extracapsular versus intracapsular allograft nephrectomy: impact on allosensitization and surgical outcomes. Can Urol Assoc J 5:49-52

38. Eng MM, Power RE, Hickey DP, Little DM (2006) Vascular complications of allograft nephrectomy. Eur J Vasc Endovasc Surg 32: 212-216

39. Sienko J, Tejchman K, Cnotliwy M, Falkowski A, Nowacki M, Ostrowski M (2006) Crossed bypass femoro-femoralis in patient with external iliac artery occlusion in the course of septic hemorrhage after renal graft explantation. Ann Transplant 11:12-14

40. McIntosh BC, Bakhos CT, Sweeney TF, DeNatale RW, Ferneini AM (2005) Endovascular repair of transplant nephrectomy external iliac artery pseudoaneurysm. Conn Med 69:465-466

41. Siddiqui AC, Lew SQ, Sarin S, Venbrux AC (2012) Emergency endovascular stenting of the right iliac artery in a patient with secondary haemorrhage following transplant nephrectomy. BMJ Case Rep 2012: bcr0220125827

42. Ayus JC, Achinger SG, Lee S, Sayegh MH, Go AS (2010) Transplant nephrectomy improves survival following a failed renal allograft. J Am Soc Nephrol 21:374-380

43. Casey MJ, Wen X, Kayler LK, Aiyer R, Scornik JC, MeierKriesche HU (2014) Prolonged immunosuppression preserves nonsensitization status after kidney transplant failure. Transplantation 98:306-311

44. Lachmann N, Schonemann C, El-Awar N, Everly M, Budde K, Terasaki PI, Waiser J (2016) Dynamics and epitope specificity of anti-human leukocyte antibodies following renal allograft nephrectomy. Nephrol Dial Transplant 31:1351-1359
45. Sener A, Khakhar AK, Nguan CY, House AA, Jevnikar AM, Luke PP (2011) Early but not late allograft nephrectomy reduces allosensitization after transplant failure. Can Urol Assoc J 5: E142-E147

46. Del Bello A, Congy-Jolivet N, Sallusto F, Guilbeau-Frugier C, Cardeau-Desangles I, Fort M, Esposito L, Guitard J, Cointault O, Lavayssiere L, Nogier MB, Blancher A, Rostaing L, Kamar N (2012) Donor-specific antibodies after ceasing immunosuppressive therapy, with or without an allograft nephrectomy. Clin J Am Soc Nephrol 7:1310-1319

47. Douzdjian V, Rice JC, Carson RW, Gugliuzza KK, Fish JC (1996) Renal retransplants: effect of primary allograft nephrectomy on early function, acute rejection and outcome. Clin Transpl 10:203-208

48. Ahmad N, Ahmed K, Mamode N (2009) Does nephrectomy of failed allograft influence graft survival after re-transplantation? Nephrol Dial Transplant 24:639-642

49. Sumrani N, Delaney V, Hong JH, Daskalakis P, Sommer BG (1992) The influence of nephrectomy of the primary allograft on retransplant graft outcome in the cyclosporine era. Transplantation 53:52-55

50. Kosmoliaptsis V, Gjorgjimajkoska O, Sharples LD, Chaudhry AN, Chatzizacharias N, Peacock S, Torpey N, Bolton EM, Taylor CJ, Bradley JA (2014) Impact of donor mismatches at individual HLAA, -B, -C, -DR, and -DQ loci on the development of HLA-specific antibodies in patients listed for repeat renal transplantation. Kidney Int 86:1039-1048

51. Wang K, Xu X, Fan M, Qianfeng Z (2016) Allograft nephrectomy vs. no-allograft nephrectomy for renal transplantation: a meta-analysis. Clin Transpl 30:33-43

52. Augustine JJ, Woodside KJ, Padiyar A, Sanchez EQ, Hricik DE, Schulak JA (2012) Independent of nephrectomy, weaning immunosuppression leads to late sensitization after kidney transplant failure. Transplantation 94:738-743

53. Woodside KJ, Schirm ZW, Noon KA, Huml AM, Padiyar A, Sanchez EQ, Sarabu N, Hricik DE, Schulak JA, Augustine JJ (2014) Fever, infection, and rejection after kidney transplant failure. Transplantation 97:648-653

54. Gregoor PJ, Kramer P, Weimar W, van Saase JL (1997) Infections after renal allograft failure in patients with or without low-dose maintenance immunosuppression. Transplantation 63:1528-1530

55. Casey MJ, Wen X, Kayler LK, Aiyer R, Scornik JC, MeierKriesche HU (2014) Prolonged immunosuppression preserves nonsensitization status after kidney transplant failure. Transplantation 98:306-311

56. Bayliss GP, Gohh RY, Morrissey PE, Rodrigue JR, Mandelbrot DA (2013) Immunosuppression after renal allograft failure: a survey of US practices. Clin Transpl 27:895-900

\section{Answers}

1. c; 2. b; 3. d 